\title{
Predicted Crop Value for Nectarines and Cling Peaches of Different Harvest Season as a Function of Crop Load
}

\author{
Gabino H. Reginato ${ }^{1}$ and Víctor García de Cortázar \\ Universidad de Chile, Casilla 1004, Santiago, Chile
}

Terence L. Robinson

Department of Horticultural Sciences, Cornell University, Geneva, NY 14456

Additional index words. light interception, fruit size, yield efficiency, thinning

\begin{abstract}
Several field experiments to assess the effect of tree size and crop load on fruit size and yield efficiency were conducted in cling peach and nectarine orchards of different harvest seasons in Chile. Trees were randomly selected in each orchard and then hand-thinned at the beginning of pit hardening to a wide range of crop loads. The fraction of above-canopy photosynthetically active radiation $(P A R)$ intercepted by the canopy $\left(P A R_{\mathrm{i}}\right)$ was determined at harvest. All fruits were counted and weighed and average fruit weight calculated. Crop load and yield were normalized by tree size measured by intercepted $\boldsymbol{P} A \boldsymbol{R}_{\mathrm{i}}$. For each orchard, the relationship between crop load and fruit size or crop load and yield efficiency was assessed by regression analysis. Fruit size distribution was calculated from fruit size adjusted for fruit load assuming a normal fruit size distribution and valued according to shipment date and price obtained from a Chilean export company. Using crop load as a covariate, fruit size adjusted for crop load was compared for nectarine and peach cultivars. Fruit size adjusted for fruit load and yield efficiency was greater with late season cultivars than the early or midseason cultivars. Predicted crop value (PCV), normalized in terms of $P A R$ intercepted, was calculated for all the cultivars. Large differences in predicted crop value were found for early, midseason, and late ripening nectarines. Early and late ripening cultivars had the highest predicted crop value, especially at lower crop loads and larger fruit sizes. The early season cultivars had high crop value as a result of higher fruit prices, whereas the late season cultivar had high crop value as a result of higher production. With cling peaches, the early season cultivar 'Jungerman' had a lower predicted crop value than the late season cultivars 'Ross' and 'Davis'. For cling peaches, the highest PCV was achieved at a relatively high crop load with high yield and small fruit size.
\end{abstract}

The price of exported fruit from Chile is a function of fruit size and shipment date with larger and earlier shipped fruit receiving the highest price per kilogram at the farm gate. For processing peaches, fruit size is not the most important determinant of price, because all fruit greater than $55 \mathrm{~mm}$ in diameter receive the same price. To improve fruit size, hand thinning is normally done in most peach and nectarine orchards. It is widely recognized that fruit size is largely determined by crop load, with larger fruit size obtained as the crop load is reduced. However, reducing crop load also reduces total yield (Blanco et al., 1995; Inglese et al., 2002; Johnson and Handley, 1989; Ojer et al., 1996, 2001; Reginato and Camus, 1993; Rowe and Johnson, 1992). Although larger fruit size results in higher prices, the true economic effect of thinning on fruit grower returns must take into account the reduction in yield that is

Received for publication 17 July 2006. Accepted for publication 26 Nov. 2006.

This research was supported in part by FONDECYT, Chile.

${ }^{1}$ To whom reprint requests should be addressed; e-mail greginat@uchile.cl. required to obtain large fruit size. The optimum economic crop load is a function of fruit size, total yield, and price. However, because different cultivars also have different yield and fruit size potentials (Inglese et al., 2002; Johnson and Handley, 1989), additional factors such as harvest date are also important in determining the farm gate crop value. Attempts to calculate optimum orchard crop load to maximize crop value by computer models have incorporated crop load and other additional factors with kiwi (Atkins, 1990) or peaches (Johnson and Rasmussen, 1990). The kiwi report considered crop load expressed as fruits per meter squared of canopy surface area, whereas the peach report used fruits per tree. Also, crop value has been determined for economic evaluation of thinning practices (Byers et al., 2005; Marini, 2000; Stover et al., 2001).

Several approaches have been used to measure crop load, including fruit number normalized by tree size based on trunk crosssectional area $\left(\mathrm{TCA} ; \mathrm{cm}^{2}\right)$, tree size based on canopy volume $\left(\mathrm{m}^{3}\right)$, canopy leaf area $\left(\mathrm{m}^{2}\right)$, fraction of light energy intercepted, or weight of wood pruned off ( $\mathrm{kg} /$ tree) with TCA being the most widely used normalizing unit as was proposed by Lombard et al. (1988). On the other hand, light interception of between $70 \%$ and $80 \%$ has been suggested as a target for orchard canopies to obtain desired yield under field conditions. This is because orchard yield is largely explained by photosynthetically active radiation $(P A R)$ interception (Robinson and Lakso, 1991) independent of training system (Iannini et al., 2000; Nuzzo et al., 2002) and is linearly related to it up to $50 \%$; after this light interception level, yield varies because other factors become limiting (Wünsche and Lakso, 2000).

The objective of this project was to predict the economic performance of nectarines and cling peaches of different harvest dates based on a standardized measure of crop load that is based on a more fundamental input variable (light intercepted by the tree) rather than trunk cross-sectional area. This information could provide basic data that could be later integrated in computer models as an aid to growers and researchers in objectively comparing management practices to improve orchard performance, make better thinning decisions, and aid in orchard design.

\section{Material and Methods}

The experiments were carried out during the 2003-2004, 2004-2005, and 2005-2006 seasons in mature commercial orchards located at the central valley of Chile (between $32^{\circ}$ and $34^{\circ} \mathrm{S}$, between $71^{\circ}$ and $\left.72^{\circ} \mathrm{W}\right)$. The nectarine cultivars used were 'Royal Glo' [early season, weeks 1 and 2 of nectarine shipments from Chile (midNovember), quad vee trained, planted at $4.8 \times 2.5 \mathrm{~m}$ ]; 'Summer Diamond' [midseason, weeks 8 and 9 (early January), central leader trained, planted at $4.5 \times 2.25 \mathrm{~m}$ ]; and 'August Red' [late season, weeks 12 and 13 of shipments (late January), perpendicular vee trained, planted at $5 \times 2 \mathrm{~m}$ ]. All nectarines were evaluated during the 2003-2004 season. A 'Ross' canning peach orchard was evaluated in 2003-2004 and 2004-2005; it was trained as a central leader planted at $4.5 \times$ $2.25 \mathrm{~m}$. In the 2005-2006 season 'Ross', 'Davis', and 'Jungerman' cling peach orchards, trained as perpendicular vee at a spacing of $5 \times 2 \mathrm{~m}$, were evaluated at a different location.

A variable number of trees between 12 and 32 were randomly selected in each orchard each year. In year 2, when 32 'Ross' trees were selected, they were separated in two tree size categories. In each group of trees of different years and cultivars, crop load of different trees was adjusted by hand thinning at the beginning of pit hardening to a wide range of crop loads, including crop loads that are usually used on trees destined for the export or processing market. PAR interception of each tree was measured right before harvest with a line quantum probe (Accupar; Decagon Devices, Pullman, Wa.; 80 sensors $1 \mathrm{~cm}$ apart); measurements were made three times a day: at solar noon, $2 \mathrm{~h}$ previous, and $4 \mathrm{~h}$ after solar noon. Row orientation was north to south and radiation 
interception was assumed symmetric between the morning and afternoon. Incident $P A R\left(P A R_{0}\right)$ was measured every $20 \mathrm{~min}$ outside the orchard. $P A R$ not intercepted $\left(P A R_{\mathrm{ni}}\right)$ was measured at ground level from five equidistant transects per tree (row middle to row middle) with one transect passing by the trunk. The fractional $P A R$ interception $\left(P A R_{\mathrm{f}}\right)$ was calculated as $1-P A R_{\mathrm{ni}} / P A R_{0}$.

Total incoming $P A R$ from bloom to maturity was very similar for the two main locations. The average total incoming $P A R$ from bloom to harvest of the latest cultivar was $9861 \mathrm{~mol} \cdot \mathrm{m}^{-2}$ in Santiago and 9987 $\mathrm{mol} \cdot \mathrm{m}^{-2}$ for Malloa. Differences between two meteorologic stations at the same latitude of each site showed less than $2 \%$ over a 30 -year average. Also, the interannual variation was less than $2 \%$ for our data. The low variability is explained by the Mediterranean climate of central Chile, where most of the rainfall and also most of the cloudy weather is concentrated in fall and winter. Hence, spring and especially summer months have a high proportion of clear days.

At harvest, all fruits were counted and weighed and average fruit weight was calculated. Individual fruit weight was determined per tree for 'August Red', 'Ross' peaches in the 2004-2005 season, and on all cling peaches cultivars in the 2005-2006 season to determine size distribution. To normalize the differences in tree density, tree size, and canopy shape of the different cultivars and orchards, fruit per tree and yield per tree were divided by the fraction of $P A R$ intercepted by the trees $\left(P A R_{\mathrm{f}} ; \%\right)$ multiplied by the land area assigned to the trees. The resulting crop load or yield efficiency values had units of fruits or kilograms per intercepted area $\left(\mathrm{m}^{2}{ }_{\text {PARi }}\right)$ stated as fruits or kilogram per intercepted square meter, respectively. The effect of crop load on yield efficiency and fruit size was analyzed by regression analysis using the procedure "dummy variable" of Infostat 2006p.2 software (UNCO, Córdoba, Argentina), which contrasts the slope of different groups ('Davis' and 'Ross') with a reference group ('Jungerman'). As a result of the similarity of slopes between cultivars, yield and fruit size comparisons between cultivars were performed by analysis of covariance (ANCOVA) using crop load as a covariate and adjusted means separated by least significant difference mean comparison test. The relationships between crop load and yield or fruit size were analyzed by least squares regression.

For nectarines, farm gate price records by shipment date (in weeks from the first nectarine shipment from Chile) and fruit size (number of fruit per 8-kg box) were obtained from a Chilean export company for the seasons 1990-2000, 2000-2001, 20012002, 2002-2003, and 2003-2004. The export season normally starts in Chile with shipments during the third week of November. Nectarines with small fruit size, corresponding to 70 series, are only exported at the beginning of the season up to week 6 because early season cultivars typically produce small fruit size and the fruit volume that is being exported is low. Nectarine farm gate return shows a sharp decrease in mid-December when the price drops from $\approx \$ 1$ US per kilogram down to $\$ 0.50$ US per kilogram (Fig. 1A). Fruit price varies according to fruit size at each shipping date with size 40 and larger having a farm gate price $\approx \$ 0.5$ per kilogram and size 50 and smaller having a price $\approx \$ 0.3$ US per kilogram (Fig. 1B).

Fruit size distribution in box size series was calculated from the fruit size adjusted for crop load assuming a normal fruit size distribution according to the methodology of Stover et al. (2001). We obtained a standard deviation (SD) of $20 \mathrm{~g}$ for 'August Red'
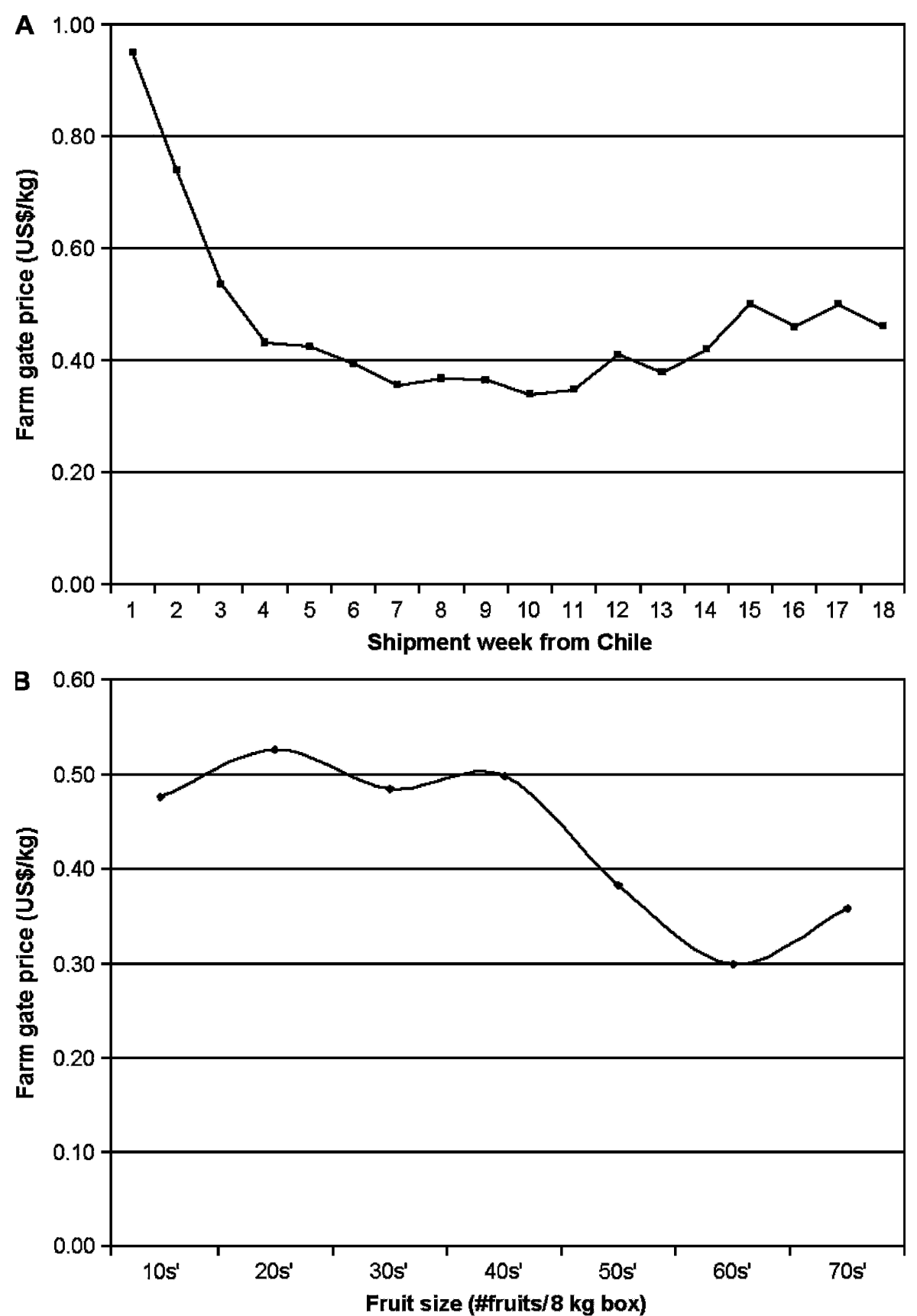

Fig. 1. Farm gate price for export market nectarines according to (A) shipment date and (B) box size of the fruit. Week $1=$ third week of November. Fruit size $70 \mathrm{~s}$ is the average for the first 6 weeks of shipments. Average price for seasons 1999-2000, 2000-2001, 2001-2002, 2002-2003, and 2003-2004. 
dollars per $10,000 \mathrm{~m}^{2}{ }_{P A R \mathrm{i}}$ ). For cling peaches, $\$ 0.16$ US per kilogram (price that is normally paid by canning industries to fruit growers in Chile for a minimum fruit size of $55 \mathrm{~mm}$ ) was used to generate predicted crop values. Because cling peach fruit size was determined by weight, a relation between fruit weight and fruit diameter was established using 50 fruits of different fruit size.

\section{Results}

\section{Yield efficiency and fruit size}

Nectarines. Yield efficiency (YE), calculated as yield per tree normalized by tree size and expressed as $\mathrm{kg} \cdot \mathrm{m}^{-2} P A R \mathrm{i}$, was linearly related to crop load calculated as fruits per tree normalized by tree size expressed as fruit $/ \mathrm{m}^{2}{ }_{P A R \text { i }}$ (Fig. 2A). Fruit size was inversely related to crop load (normalized as before) (Fig. 2B), and the different cultivars showed similar slopes of the response regardless of their harvest maturity date, but the intercepts were different denoting the different potential fruit size of the different cultivars. Because no differences among cultivars were detected in the slopes of the response of fruit size or yield efficiency to crop load, differences between cultivars in potential fruit size and yield efficiency could be explained by ANCOVA using crop load as covariate. This analysis showed fruit size was largest for the late season 'August Red' nectarine and smallest for the early season 'Royal Glo' nectarine (Table 1). Smaller differences were detected between the early and midseason cultivars than between the late season and early season cultivars. 'Summer Diamond' had only $11 \%$ larger fruit and $18 \%$ more yield than 'Royal Glo', whereas 'August Red' had 50\% larger fruit and nearly $100 \%$ more yield than 'Royal Glo'.

Canning peach. As was found for nectarines, there were no significant differences in the slopes of the response curves among different cultivars for yield efficiency and fruit size as a function of increasing crop load $(P=0.17$ and $P=0.94$ for fruit size and yield efficiency, respectively, when the slope of 'Ross' was compared with Jungermann) (Fig. 3A, B). The canning peach cultivars showed similar slopes to nectarine cultivars, between -0.8 and $-0.9 \mathrm{~g} \cdot \mathrm{m}^{-2} P A R \mathrm{i}$ for fruit size and between 0.08 and $0.1 \mathrm{~kg} \cdot \mathrm{m}^{-2} P A R$ f for $\mathrm{YE}$ (Figs. 2 and 3; Tables 1 and 2). ANCOVA showed when the effect of crop load was removed, there were significant differences in yield efficiency and fruit size between the early and late season peach cultivars. 'Ross' and 'Davis' were $15 \%$ more productive and had larger fruit size than the early season cultivar Jungerman (Table 2).

When the data for 'Ross' and 'Davis' peach was combined for all seasons and all orchards, the differences in fruit yield efficiency (Fig. 4A) or fruit size (Fig. 4B) were largely explained by crop load defined as fruit number per intercepted meter squared $\left(\mathrm{m}^{2}{ }_{P A R \mathrm{i}}\right)$. In the 2003-2004 season, the range of crop loads was relatively low (between 18 and 47 fruits $/ \mathrm{m}^{2}{ }_{P A R \mathrm{i}}$ ), whereas in the 2006
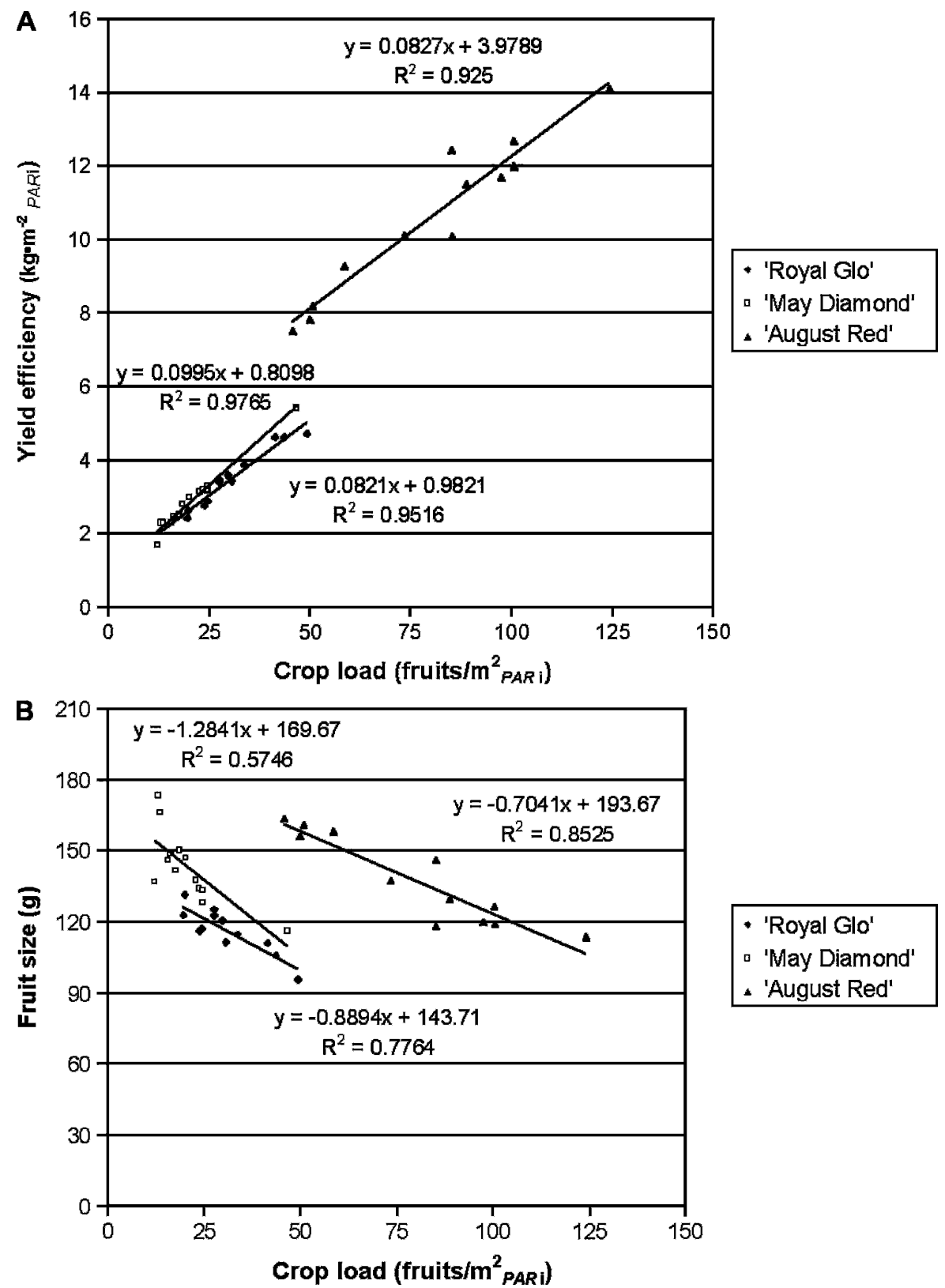

Fig. 2. Yield efficiency expressed as (A) $\mathrm{kg} \cdot \mathrm{m}^{-2}{ }_{P A R \mathrm{i}}$ and $(\mathbf{B})$ fruit size as a function of increasing crop load expressed as fruit $/ \mathrm{m}^{2}$ PARi for nectarines of different harvest seasons in 2003-2004.

Table 1. Fruit size adjusted for crop load and yield efficiency for nectarines of different harvest seasons in Chile.

\begin{tabular}{lcccc}
\hline & & & \multicolumn{2}{c}{ Relative to Royal Glo (\%) } \\
\cline { 3 - 5 } Cultivar & Fruit size $(\mathrm{g})$ & Yield efficiency $\left(\mathrm{kg} \cdot \mathrm{m}^{-2}{ }_{P A R i}\right)$ & Fruit size & Yield efficiency \\
\hline Royal Glo & $113.8 \mathrm{a}^{\mathrm{z}}$ & $3.76 \mathrm{a}$ & 100.0 & 100.0 \\
S. Diamond & $126.3 \mathrm{~b}$ & $4.45 \mathrm{~b}$ & 110.9 & 118.3 \\
August Red & $170.3 \mathrm{c}$ & $7.29 \mathrm{c}$ & 149.6 & 193.9 \\
$\begin{array}{l}\text { Covariate coefficient } \\
\left.\quad \text { Crop load (fruit } / \mathrm{m}^{2}{ }_{P A R i}\right)\end{array}$ & $-0.9^{\mathrm{y} *}$ & & & \\
\hline
\end{tabular}

${ }^{2}$ Means are adjusted for the effect of crop load by covariance analysis. Different letters in a column indicate significant differences by least significant difference test $P \leq 0.05(\mathrm{n}=12)$.

${ }^{y}$ Value is the coefficient for the response to the covariate, calculated by analysis of covariance procedure. *Indicates statistical significance at $P \leq 0.01$.

season, the range of crop loads was intermediate (between 36 and 86), but in the 20042005 season, the trees were practically overloaded with a range from 50 to 160 fruits/ $\mathrm{m}_{P A R \mathrm{i}}^{2}$. There was no difference in the regression lines for 'Davis' and 'Ross'; thus, a common response curve is presented (Fig. 4). In contrast, but in agreement with the differences detected by ANCOVA, 'Jungerman' showed a similar but lower trend having 
A
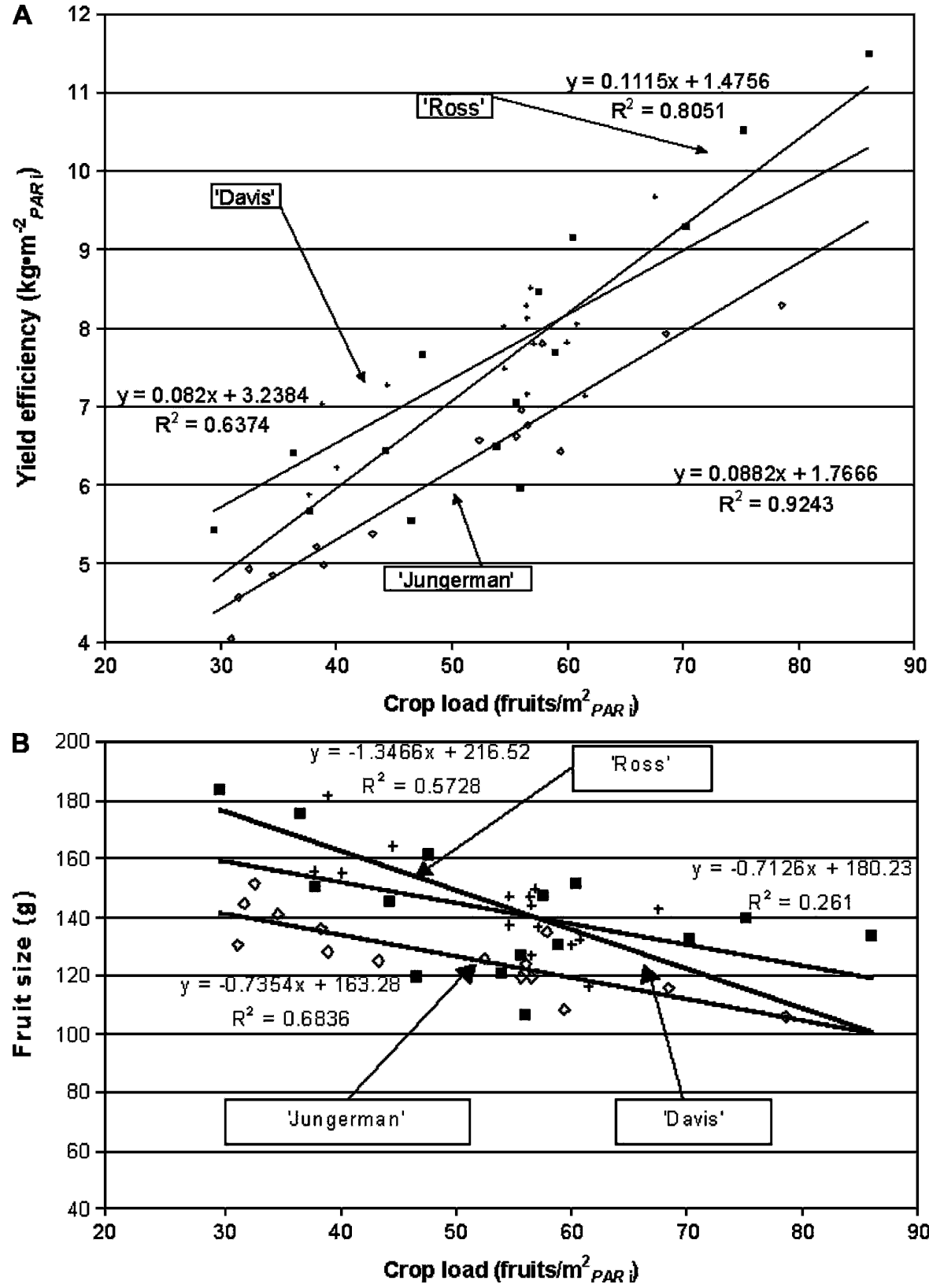

Fig. 3. Yield efficiency expressed as (A) $\mathrm{kg} \cdot \mathrm{m}^{-2}{ }_{P A R \mathrm{i}}$ and (B) fruit size as a function of increasing crop load, expressed as fruit $/ \mathrm{m}^{2}{ }_{P A R \mathrm{i}}$ for cling peaches of different harvest seasons in 2005-2006.

Table 2. Fruit size adjusted for crop load and yield efficiency for cling peaches of different harvest season cling peaches in Chile.

\begin{tabular}{lcccc}
\hline & & & \multicolumn{2}{c}{ Relative to Jungerman (\%) } \\
\cline { 3 - 5 } Cultivar & Fruit size $(\mathrm{g})$ & Yield efficiency $\left(\mathrm{kg} \cdot \mathrm{m}^{-2}{ }_{P A R i}\right)$ & Fruit size & Yield efficiency \\
\hline Jungerman & $124.5 \mathrm{a}^{\mathrm{z}}$ & $6.41 \mathrm{a}$ & 100.0 & 100.0 \\
Davis & $143.2 \mathrm{~b}$ & $7.34 \mathrm{~b}$ & 115.0 & 114.5 \\
Ross & $145.4 \mathrm{~b}$ & $7.51 \mathrm{~b}$ & 116.8 & 117.2 \\
Covariate coefficient & & & & \\
$\quad$ Crop load (fruit $\left./ \mathrm{m}^{2}{ }_{P A R i}\right)$ & $-0.8^{\mathrm{y} *}$ & $0.1 *$ & & \\
\hline
\end{tabular}

${ }^{2}$ Means are adjusted for the effect of crop load by covariance analysis. Different letters in a column indicate significant differences by least significant difference test $P \leq 0.05(\mathrm{n}=12)$.

${ }^{\mathrm{y}}$ Value is the coefficient for the response to the covariate, calculated by analysis of covariance procedure. *Indicates statistical significance at $P \leq 0.01$.

lower YE and smaller fruit size at similar crop loads. The curvilinear response of yield efficiency or fruit size as a function of crop load, which was detected for cling peaches, was only apparent when the data for all years and all orchards were put together as shown in Figure 4. A linear response was obtained for different cultivars when a narrower range of crop load was considered (Fig. 3) or with nectarines (Fig. 2).

\section{Crop value}

Predicted crop value (PCV) was related to crop load, but different responses were obtained for each of the three nectarine cultivars (Fig. 5). The small fruit size, midseason cultivar, 'Summer Diamond', has the lowest optimum PCV, $\approx \$ 3000 \mathrm{US} / \mathrm{ha}_{P A R \mathrm{i}}$. A much higher optimum predicted crop value, between $\$ 14,000$ and $\$ 17,000 \mathrm{US} / \mathrm{ha}_{P A R \mathrm{i}}$, was estimated for the earlier and later cultivars. For all three cultivars, the optimum crop value was expected at relatively low crop loads where there was less yield but larger and more valuable fruit. With increasing crop loads, there was a dramatic reduction in predicted crop value. With all three cultivars, we found an optimum PCV that was coincident with the lowest crop load levels used in this trial, $\approx 20$ fruits $/ \mathrm{m}^{2}$ PARi with 'Royal Glo' and 'Summer Diamond' and 55 fruits $/ \mathrm{m}^{2}$ PARi for 'August Red' (Fig. 5).

With the three cling peach cultivars, the opposite result was obtained in which PCV increased as crop load increased over most of the range used in the experiment (Fig. 6). At the highest crop loads, the curves showed a plateau phase, $\approx 80$ fruits $/ \mathrm{m}^{2}{ }_{P A R \mathrm{i}}$ (Fig. 6). 'Ross' and 'Davis' had a higher predicted crop value at each crop load than did 'Jungerman'. The increasing crop value phase of each curve was associated with increasing crop and decreasing fruit size but not beyond the acceptable limit of the industry $(55 \mathrm{~mm})$. In the plateau phase, increasing crop load resulted in fruit being rejected for small fruit size but compensated for with increasing yield. The curves show a hint of a descendant phase, which is clearly dominated by the rejected small fruit (Fig. 6).

\section{Discussion}

Our study shows cling peach and nectarine fruit size is inversely and linearly or curvilinearly related with crop load as it has been previously shown by Blanco et al. (1995), Inglese et al. (2002), and Rowe and Johnson (1992). In addition, the relationships we found were different according to the harvest season of the cultivar as shown by Johnson and Handley (1989). In earlier reports, crop load was expressed as fruits per tree or fruits per unit of TCA (Blanco et al., 1995; Inglese et al., 2002; Johnson and Handley, 1989; Marini, 2000; Rowe and Johnson, 1992). Using the number of fruits per tree has been very useful under highly uniform conditions in which negligible differences in tree size are expected. Where significant differences in tree size are expected, it is essential to normalize crop load by tree size. Autio et al. (1996) recognized normalizing crop load by tree size, expressed as fruit $/ \mathrm{cm}^{2}$ TCA, is an incorrect procedure as the tree gets older. The relationship between TCA and actual tree size is lost because tree containment pruning modifies the relationship. This may be true in mature peach trees in which very intensive annual pruning is practiced. Our study showed expressing crop load, normalized 

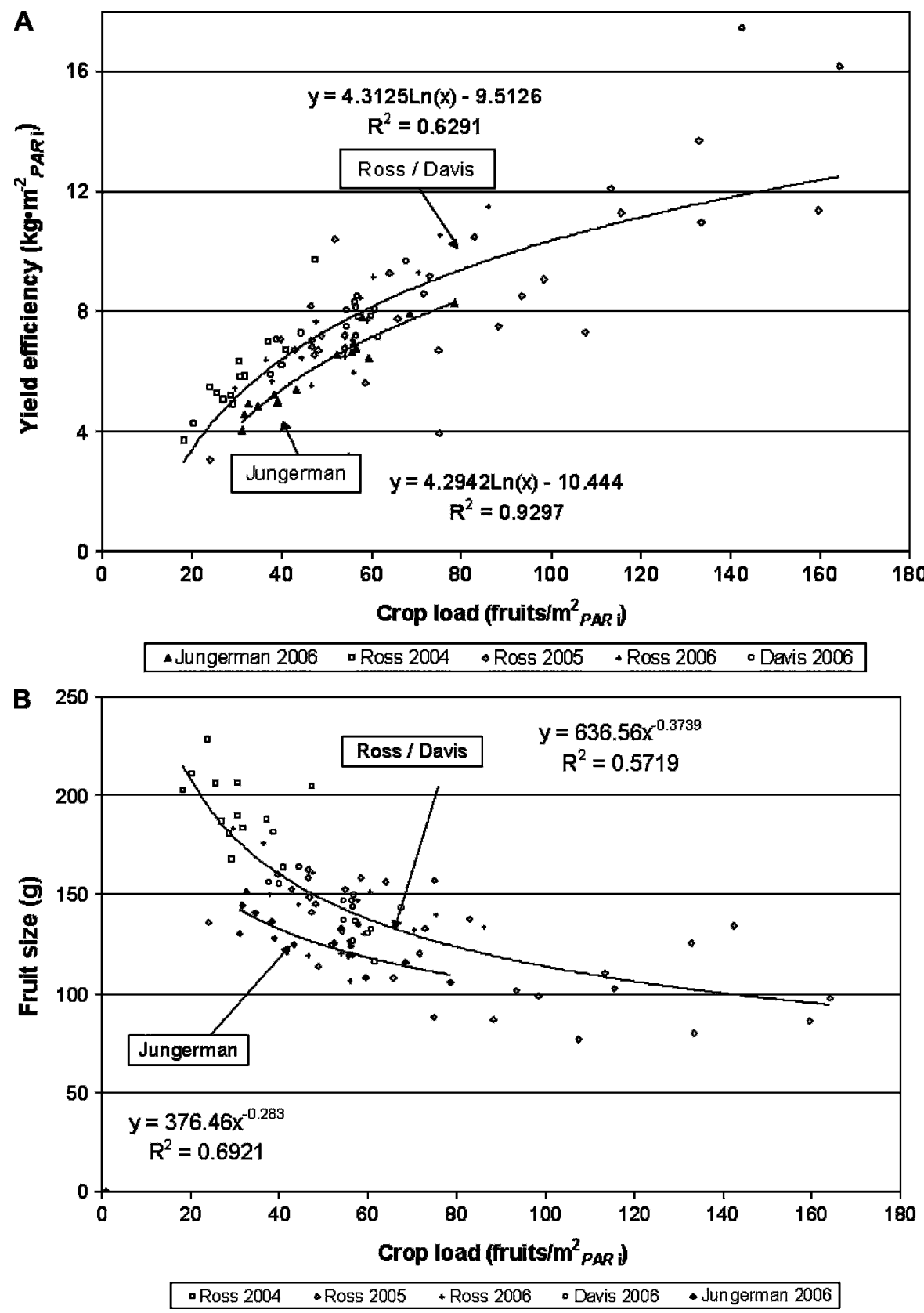

Fig. 4. Yield efficiency expressed in (A) $\mathrm{kg} \cdot \mathrm{m}^{-2}{ }_{P A R \mathrm{i}}$ and (B) fruit size as a function of crop load expressed as fruit $/ \mathrm{m}^{2}{ }_{P A R \mathrm{i}}$ for cling peaches grouped by harvest season. Seasons 2003-2004, 2004-2005, and 2005-2006.

by tree size, as measured in terms of radiation intercepted by the trees, results in a more realistic comparisons between the efficiencies of different orchards. It allows comparisons under similar conditions of tree coverage minimizing the differences among tree density, tree shape, or tree size. For 'Ross' peach when data from different seasons, training systems, orchard age, or orchard management were analyzed, our data show a single response curve as a function of crop load. This approach should be useful in evaluating differences between rootstocks by keeping tree size differences out of the analysis.

Apple tree yield can be explained as a linear function of the fraction of $P A R$ intercepted by the tree even when different
Johnson and Handley, 1989; Rowe and Johnson, 1992). In this experiment, we described yield response to various crop loads for nectarine cultivars of different harvest seasons and then compared them independent of tree size. In 'Ross', we included 3 years of data and a different training system in year 3 . Even with such differences, a single response curve was obtained, which allowed the variation in fruit size or yield efficiency over years to be described as a function of increasing crop load expressed per unit of intercepted light per land area. This approach accounts for the two major factors affecting yield (light interception and crop load) and allows a more general predictive relationship to be established for each growing area. We predict under similar climates like our experiments, the same cultivar would give similar or complementary relationships of crop load and yield efficiency or fruit size.

In most experiments that have evaluated the effect of crop load on fruit size and yield efficiency, researchers have shown a linear response curve (Johnson and Handley, 1989). Similarly, our experiments showed the response to increasing crop load was a linear response of yield efficiency or fruit size. This was true for each of the nectarines and the cling peaches in each of the three seasons; and in our studies and those of others, comparing cultivars, rootstocks, or even management practices (Johnson and Handley, 1989), differences in the slopes between treatments are often detected for different cultivars. However, our data indicated over a very broad range of crop loads, the relationship of yield efficiency or fruit size with crop load is curvilinear; others have also found a curvilinear response with fruit size and yield when a wide range of crop loads has been imposed in their experiments (Blanco et al., 1995; Inglese et al., 2002; Johnson and Handley, 1989; Rowe and Johnson, 1992). Over narrower ranges of crop load, the response of both nectarines and cling peaches to crop load was linear.

Our data indicate that differences in slope can be obtained depending on the crop load range of the experiment. With 'Ross', 'Davis', and 'Jungerman' peach, when the range of crop loads was on the low end of the scale, a higher slope was observed than when the range of crop loads was on the higher range of the scale (Fig. 4). This becomes important when analyzing experimental data using covariance analysis. Covariance analysis should only be used if the slopes of the regression lines of the response variable as function of the covariate are not statistically different among treatments (Marini et al., 2002). This is likely to be true only when the treatments have relatively similar crop load as was the case for the cling peach experiment in season 3 .

Also, ANCOVA assumes the covariate should not be influenced by the application of the treatments, a situation that was observed when we analyzed the results for nectarines. However, ANCOVA analysis can also be useful as a tool to explain experimental 


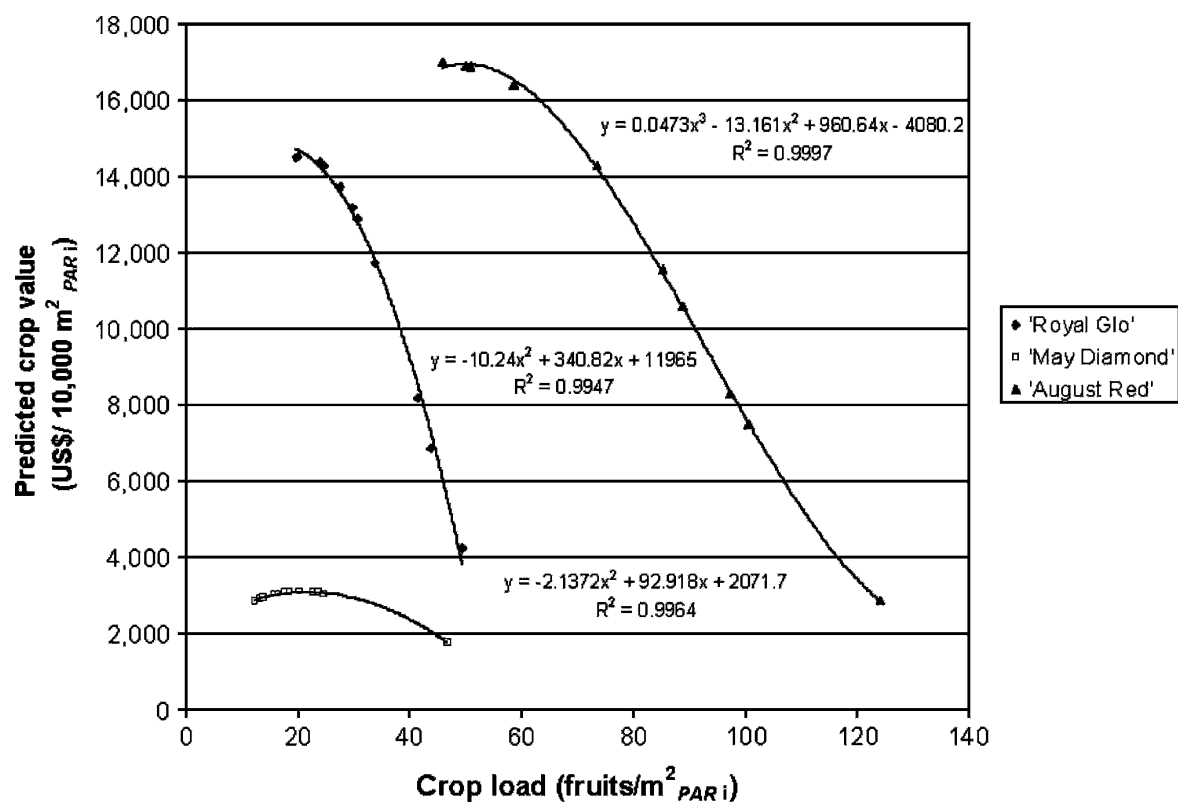

Fig. 5. Predicted crop values expressed as US $\$ / \mathrm{ha}_{P A R \mathrm{i}}$ for different nectarine cultivars as a function of crop load expressed as fruit $/ \mathrm{m}^{2} P A R$.

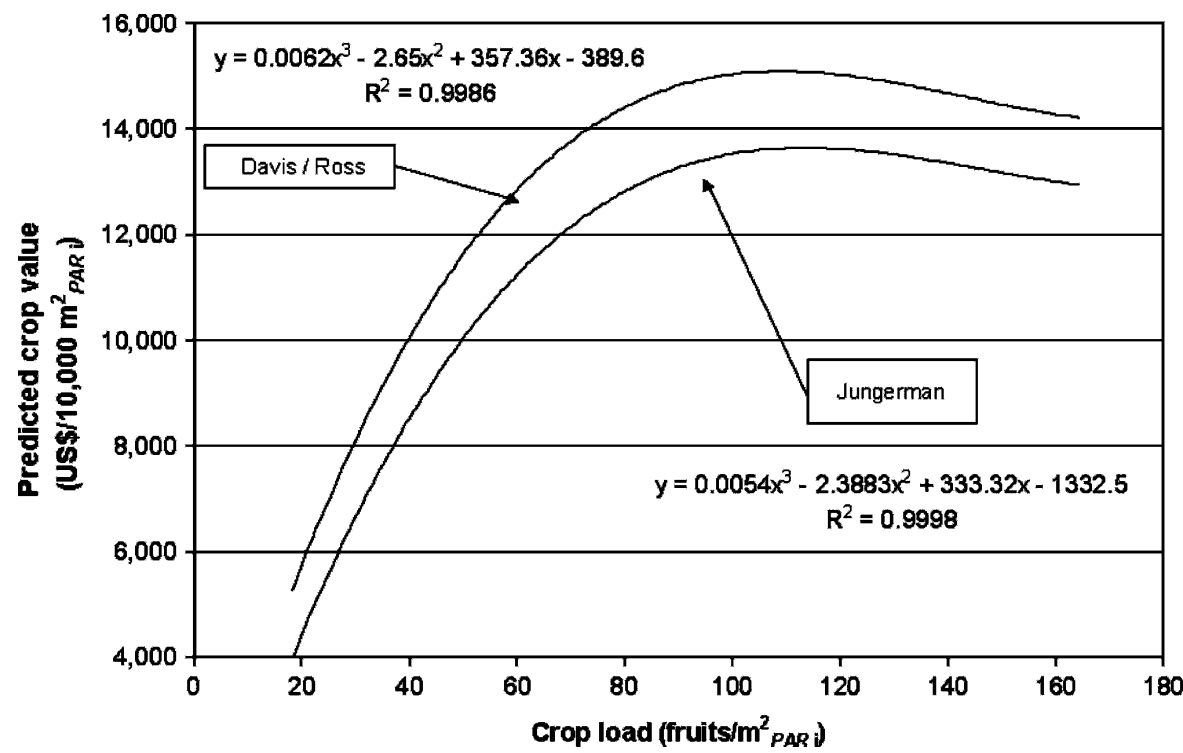

Fig. 6. Predicted crop values expressed as US $\$ / h a_{P A R \mathrm{i}}$ for cling peach cultivars of different harvest season as a function of crop load expressed as fruit $/ \mathrm{m}^{2} P A R$.

results, and in this case, the covariate could be affected by the treatments (Clewer and Scarisbrick, 2001; Gomez and Gomez, 1984). In our study, although nectarine fruit size and yield efficiency could be explained as a response to crop load, using ANCOVA to adjust means, fruit size, and yield efficiency resulted in unreasonable values for 'S. Diamond' and 'Royal Glo' because they are adjusted to a crop load value that is out of the range of our experimental data for both cultivars. Thus, fruit size and yield efficiency calculated for those cultivars should not be considered in absolute terms.

In addition, covariance analysis takes into account only a linear response between the response variable and the covariate. With a very broad range of crop loads as we showed crop load range was similar to the cling peaches. 'August Red' had a similar linear fruit size and YE response to increasing crop load as the cling peaches.

The most important practical use of the multiyear relationships of crop load and fruit size or yield efficiency was the calculation of $\mathrm{PCV}$ as a function of crop load for nectarines and cling peaches of different harvest seasons. Our results show for nectarines, relatively low crop loads are optimum for early and midseason cultivars, but with late season nectarines, the optimum crop load is much higher. In addition, the greatest returns to the fruit grower are with early season cultivars in which the price is high and with late season cultivars in which the price is lower but higher yield is possible. In contrast, with cling peaches, the optimum crop load was very high and was similar for the early and late season cultivars. These results should be widely applicable in climates and markets similar to Chile's and can serve as a guide to fruit growers to develop optimum thinning strategies with nectarines and cling peaches of different harvest seasons.

Standard deviation is an important variable in calculating packout and crop value. Our estimate of SD for nectarines $(20 \mathrm{~g}$ ) was lower than those reported by Johnson and Handley (1989) (32-50 g for peaches). The crop load-dependent SD, which we found for cling peaches (15-45 g), was similar to those previously reported by Johnson and Handley (1989). Johnson and Rasmussen (1990) evaluated the effect of different SD values on the calculated net revenues with their model finding net revenue showed poor sensitivity to this variable in their model.

It can be argued that expressing yield and PCV value as a function of intercepted $P A R$ by the trees may not really reflect how much a grower can obtain in a specific orchard. However, this variable effectively normalizes different tree sizes and allows comparisons for fruit size or yield efficiency between cultivars, taking into account different yields, management conditions, fruit size, and fruit price. The response of yield efficiency and fruit size to changes in crop load can be incorporated into the one variable that is most important to the fruit grower, PCV. In addition, if PCV is to be calculated, the analysis must consider the slopes of the fruit size and crop load response, because this is one of the most important factors that determines the net income of differentially thinned trees (Johnson and Rasmussen, 1990).

To extend this analysis to include additional cultivars or other climates will require future experiments to include a wide range of crop load, an analysis of the slope response to increasing crop load, and a determination of the SD for fruit size, which is normally not measured in thinning trials.

To rationalize the PCV unit (US $\$ / \mathrm{ha}_{P A R \mathrm{i}}$ ) back to the actual orchard where the data were recorded, it is necessary to divide the value by the actual light interception fraction for that orchard. Thus, for an orchard intercepting $25 \%$ or $50 \%$ of the incident $P A R$, the 
calculated crop value represents the crop value on 4 or 2 ha, respectively. A theoretical optimum potential orchard performance and crop value for a specific cultivar and area (1 ha, for example) can be estimated by multiplying the PCV from our data by 0.70 to $0.80 P A R$ interception fraction, which is the recommended optimum interception fraction to optimize yield and fruit quality.

\section{Conclusions}

Fruit size and yield efficiency can be explained as a function of crop load expressed as fruit $/ \mathrm{m}^{2}$ PARi . This allows performance comparisons of multiple cultivars for yield capacity and fruit size potential. Yield efficiency can be objectively compared using intercepted radiation as the normalizing unit. With this methodology, PCV can be established for different growing conditions leading to improved crop load management. This will permit growers to optimize the net return that can be obtained for a specific orchard. Understanding how crop value is affected by crop load for different cultivars can lead to better decisions in the design and establishment of new orchards.

\section{Literature Cited}

Atkins, T.A. 1990. Using crop models to predict orchard profitability. Acta Hort. 276:363-370.

Autio, W.R., D.W. Greene, and W.J. Lord. 1996. Performance of McIntosh apples trees on seven rootstocks and a comparison of methods of productivity assessment. HortScience 31: 1160-1163.
Barritt, B., C. Rom, B. Konishi, and M. Dilley. 1991. Light level influences spur quality and canopy development and light interception influence fruit production in apple. HortScience 26:993-999.

Blanco, A., A. Pequereul, J. Val, E. Monge, and J. Gomez Aparisi. 1995. Crop-load effects on vegetative growth, mineral nutrient concentration and leaf water potential in 'Catherine' peach. J. Hort. Sci. 70:623-629.

Byers, R., G. Costa, and G. Vizzotto. 2005. Flower and fruit thinning of peach and other Prunus Hort. Rev. (Amer Soc Hort Sci) 28:351-391.

Clewer, A.G. and D.H. Scarisbrick. 2001. Practical statistics and experimental design for plant and crop science. Wiley, U.K.

Gomez, K.A. and A.A. Gomez. 1984. Statistical procedures for agricultural research. 2nd edition. Wiley, USA.

Iannini, C., B. Cirillo, B. Basile, and M. Forlani. 2000. Estimation of nectarine yield efficiency and light interception by the canopy in different training systems. Acta Hort. 592:357-365.

Inglese, P., T. Caruso, and G. Gugliuzza. 2002. Crop load and rootstock influence on dry matter partitioning in trees of early and late ripening peach cultivars. J. Amer. Soc. Hort. Sci. 127:825-830.

Johnson, R.S. and D.F. Handley. 1989. Thinning response of early, mid-, and late- season peaches. J. Amer. Soc. Hort. Sci. 114:852-855.

Johnson, R.S. and J. Rasmussen. 1990. Peach optimization model. Acta Hort. 276:247-255.

Lombard, P.B., N.W. Callan, F.G. Dennis, N.E. Looney, G.C. Martin, A.R. Renquist, and E.A. Mielke. 1988. Towards a standardized nomenclature in determining fruit and nut tree yield performance. HortScience 23:813-817.

Marini, R. 2000. Pruning peach trees to reduce thinning costs and improve fruit size. Virginia Fruit 1:1-2,4.
Marini, P.R., J.A. Barden, J.A. Cline, R.L. Perry, and T. Robinson. 2002. Effect of apple rootstock on average 'Gala' fruit weight at four locations after adjusting for crop load. J. Amer. Soc. Hort. Sci. 127:749-753.

Nuzzo, V., B. Dichio, and C. Xyloyannis. 2002. Canopy development and light interception in peach trees trained to transverse $\mathrm{Y}$ and delayed vase in the first four years after planting. Acta Hort. 592:405-412.

Ojer, M., C. Arjona, and G. Reginato. 2001. Incidencia de la carga inicial de frutos sobre la producción y la calidad de frutos en duraznero cv. Bowen. Invest. Agr.: Prod. Prot. Veg. $16: 25-35$.

Ojer, M., G. Reginato, C. Arjona, D. Cantú, and P. Minatelli. 1996. Determinación de la capacidad de carga frutal, en un huerto de durazneros cvs. Bowen y Andross. Investigación Agrícola $16: 1-8$

Reginato, G. and J.L. Camus. 1993. Efecto de la fecha e intensidad de raleo sobre la producción y crecimiento del duraznero cv. Angelus. Investigación Agrícola 13:1-8

Robinson, T.L. and A.N. Lakso. 1991. Bases of yield and production efficiency in apple orchard system. J. Amer. Soc. Hort. Sci. 116:188-194.

Rowe, R.N. and R. Johnson. 1992. The interactions between fruit number, tree size and the yield and fruit size of Fantasia nectarine. Acta Hort. 315:171-176.

Stover, E., F. Wirth, and T. Robinson. 2001. A method for assessing the relationship between crop load and crop value following fruit thinning. HortScience 36:157161.

Wünsche, J.N. and A.N. Lakso. 2000. Apple tree physiology-implications for orchard and tree management. Compact Fruit Tree 33 $82-85$. 